\title{
A Qualitative Study of Patient Perspectives about Hypertension
}

\author{
Emily P. Jolles, ${ }^{1}$ Raj S. Padwal, ${ }^{2}$ Alexander M. Clark, ${ }^{3}$ and Branko Braam ${ }^{1}$ \\ ${ }^{1}$ Division of Nephrology and Immunology, Department of Medicine, University of Alberta, Edmonton, AB, Canada T6G $2 G 3$ \\ ${ }^{2}$ Division of General Internal Medicine, Department of Medicine, University of Alberta, Edmonton, AB, Canada T6G $2 G 3$ \\ ${ }^{3}$ Faculty of Nursing, University of Alberta, Edmonton, AB, Canada T6G $2 G 3$
}

Correspondence should be addressed to Branko Braam; branko.braam@ualberta.ca

Received 11 January 2013; Accepted 5 February 2013

Academic Editors: G. Davidai, H. Komine, and A. A. Noorbala

Copyright (C) 2013 Emily P. Jolles et al. This is an open access article distributed under the Creative Commons Attribution License, which permits unrestricted use, distribution, and reproduction in any medium, provided the original work is properly cited.

\begin{abstract}
To understand hypertensive patients' perspectives regarding blood pressure and hypertension treatment, this qualitative study applied semistructured interviews of hypertensive patients. Participants were recruited from two hypertension clinics at the University of Alberta in Edmonton, Canada. To be eligible for inclusion, patients had to be aged 18 years or older, diagnosed with hypertension by a healthcare provider, and currently taking an antihypertensive medication. Participants were stratified in the analysis according to blood pressure control. Twenty-six patients (mean age 57;62\% female) were interviewed, of which $42 \%$ were on target and 58\% were not. Three underlying themes emerged from the interviews: (a) knowledge of blood pressure relating to diagnosis and management and control of hypertension, (b) integration of hypertension management into daily routine, and (c) feelings and beliefs of wellness. None of the above themes were associated with better control. Knowledge gaps were found, which emphasize the need for further patient education and physician training. Feelings and beliefs of wellness, and not knowledge, were important factors in home assessment of blood pressure. The absence of connections between control of hypertension and the identified domains indicates that current approaches could benefit from the development of a more personalized approach for education and communication.
\end{abstract}

\section{Introduction}

Hypertension is highly prevalent, and although rates of detection and control of hypertension are improving in many countries, uncontrolled hypertension remains common [1] and medication and lifestyle adherence remains low. Nonadherence leads to substantial avoidable healthcare costs [2] because of inefficiencies in care delivery, discarded medications, and expenditures related to preventable hypertensionrelated sequelae [3]. Nonpharmacological interventions to improve hypertensive medication adherence are usually very complex involving both educational and behavioural interventions and data examining efficacy have not been consistent [4]. Improved understanding of the psychology of the hypertensive patient seems desirable.

A number of patient-related barriers to optimizing blood pressure (BP) control have been identified. These include lack of patient knowledge, difficulty of treating an asymptomatic condition, personal beliefs that conflict with hypertension treatment goals, and other patient issues such as social economic status, cultural beliefs, access to care, psychosocial factors, and health literacy [5]. Additional obstacles include a lack of communication and trust between patients and care providers, high medication costs, high drug burden, failure to attend follow-up appointments, and discontinuation of therapy due to drug side effects [5-10]. There is limited data available about patients' personal perspectives regarding obstacles to hypertension control [11, 12]. We therefore performed a qualitative study consisting of semistructured interviews to explore hypertensive patients' views on their disease state and issues related to optimizing BP control.

\section{Methods}

2.1. Patient Recruitment and Inclusion. Patients were recruited from two hypertension clinics at the University of Alberta (Edmonton, Midwestern Canada). Inclusion criteria were age over 18 years; ability to read, speak, and write English; hypertension defined as either having a BP over the desired target, 
patients' BP was either $<140 / 90 \mathrm{~mm}$ Hg or $<130 / 80 \mathrm{~mm} \mathrm{Hg}$ in case of $\mathrm{DM}$ or $\mathrm{CKD}$, or being on antihypertensive therapy; absence of cognitive dysfunction; use of at least one hypertensive drug; agreeing to sign informed consent. Each patient was mailed a pamphlet as part of the appointment scheduling, and, during the appointment, recruiting physicians asked patients whether they would be willing to participate in the study. Written information about the study was then provided by the study coordinator and informed consent was obtained. Patients received a $\$ 50$ reimbursement for participation in the study for the time spent on the interview and costs of parking and travel. Ethical approval was obtained from the University of Alberta Health and Research Ethics Board; all participating patients signed consent to participate in the study.

2.2. Conducting Qualitative Interviews. Patients were consented and interviewed by EPJ, and all interviews were audio-taped and transcribed verbatim. The interviewer stated that she was interested in patients' perspective on hypertension management and ensured confidentiality that patients' answers would not be reported back to the referring doctor. Interviews were conducted in a neutral, nonclinical setting. The sample was substratified according to hypertension control (controlled versus uncontrolled). Patients were considered "on target" if BP was either $<140 / 90 \mathrm{~mm} \mathrm{Hg}$ or $<130 / 80 \mathrm{~mm} \mathrm{Hg}$ in case of DM or renal impairment defined by estimated GFR $<90 \mathrm{~mL} / \mathrm{min} / 1.72 \mathrm{~m}^{2}$ as derived from the MDRD equation.

An interview topic guide was developed using the current literature in the field and based on expert opinion. Interviews were semistructured, 30-60 minutes in duration, and designed to elicit patients' perspectives using open-ended questions to trigger responses and prompts/probes as necessary for clarification purposes. Two pilot interviews were conducted and transcribed, after which the interview guide was refined, and then the remaining interviews were conducted. The pilot interviews were included in the analysis. Specific interview topics were definitions of high BP, the consequences of uncontrolled hypertension, current BP in relation to targets, methods to lower $\mathrm{BP}$, medication adverse effects, and barriers to and facilitators of routine drug intake and adherence.

2.3. Analysis. Data analysis was organized using NVIVO8 (QSR International), a computer program that organizes repeating themes and aids in the coding of transcripts. Themes were derived from a review of the literature and by cataloguing reoccurring themes from the interviews [13]. Additionally, descriptive statistics such as lab values and demographic variables were extracted from charts and added to the dataset for analysis. To ensure rigour, a selection of early transcripts was reviewed independently by 2 researchers (E. P. Jolles and A. M. Clark). Themes emerging from the interviews were used to create categories and subcategories for the coding framework. Interviews were conducted until data saturation was reached and new themes were no longer emerging.
TABLE 1: Baseline characteristics.

\begin{tabular}{lc}
\hline Risk factor & Values \\
\hline Female (\%) & $62 \%$ \\
Age, years & $57 \pm /-16$ \\
SBP, mm Hg & $134 \pm /-17$ \\
DBP, mm Hg & $79 \pm /-11$ \\
BP at or above target & $58 \%$ \\
Total cholesterol, mmol/L* & $4.9 \pm /-.93$ \\
LDL cholesterol, mmol/L & $2.8 \pm /-.93$ \\
Creatinine, mmol/L & $93 \pm /-29$ \\
eGFR, mL/min/1.73 m ${ }^{2}$ & $72 \pm /-23$ \\
Diagnosis of diabetes mellitus & $12 \%$ \\
Diagnosis of prediabetes & $23 \%$ \\
Fasting glucose, mmol/L & $5.8 \pm /-1.5$ \\
BMI > 30 kg/m ${ }^{2}$ & $42 \%$ \\
Smoking: never/past/current & $58 \% / 35 \% / 7 \%$ \\
Framingham cardiac event score ${ }^{*}$ & $8 \% / 23 \% / 65 \%$ \\
High/moderate/low &
\end{tabular}

${ }^{*}$ One patient's information not available.

\section{Results}

3.1. Patient Population. Twenty-six patients (62\% female; majority Caucasian), aged $57 \pm 16$ years (range 26-84), were included in analysis. Baseline characteristics are provided in Table 1. Sixty-five percent of the participants were prescribed more than one drug for hypertension. The most commonly prescribed antihypertensive drug class was inhibitors of the renin-angiotensin system (62\%). Forty-two percent of the patients were at or below target BP levels.

3.2. Qualitative Interviews. Three underlying themes emerged from the interviews: knowledge of $\mathrm{BP}$, management integration of hypertension management into the daily routine, and individual patient feelings and beliefs of wellness that impact hypertension control (Figure 1). Detailed themes mentioned most often by patients are listed in Table 2 and are stratified by patients on and off target.

3.3. Knowledge about Hypertension. Patients widely reported that hypertension was a health concern to them. However, while patients possessed some general knowledge of their condition and hypertension, the level and sophistication of this knowledge varied widely (Table 3). About half (54\%) of patients were able to recall that optimal BP was $120 / 80 \mathrm{~mm} \mathrm{Hg}$ or could identify their target BP threshold $(<140 / 90 \mathrm{~mm} \mathrm{Hg}$ and $<130 / 80 \mathrm{~mm} \mathrm{Hg}$ for those with DM or CKD). Neither patient sex nor achieved BP levels were related to knowledge about targets. However, most patients (92\%) were aware of methods that could or would be likely to lower their BP. The majority (92\%) knew their current BP. Seventy-three percent of patients could recall consequences of hypertension, such as cardiovascular events and renal disease, but patients struggled to define hypertension. 
TABLE 2: Themes mentioned by patient population.

\begin{tabular}{|c|c|c|c|}
\hline Theme and subtheme & Total & On target & Not on target \\
\hline$N$ & 26 & 11 & 15 \\
\hline \multicolumn{4}{|l|}{ Attitude } \\
\hline Wishes to lower or eliminate the need for medication & $62 \%$ & $27 \%$ & $35 \%$ \\
\hline Holistic approach & $30 \%$ & $15 \%$ & $15 \%$ \\
\hline Belief in the benefits of medication & $80 \%$ & $38 \%$ & $42 \%$ \\
\hline Mention family history of HTN & $61 \%$ & $23 \%$ & $38 \%$ \\
\hline \multicolumn{4}{|l|}{ Knowledge } \\
\hline BP consequences & $73 \%$ & $31 \%$ & $42 \%$ \\
\hline Home monitoring & $88 \%$ & $42 \%$ & $46 \%$ \\
\hline Current BP & $92 \%$ & $42 \%$ & $50 \%$ \\
\hline Ways to lower BP & $85 \%$ & $38 \%$ & $47 \%$ \\
\hline Side effects & $80 \%$ & $42 \%$ & $38 \%$ \\
\hline Recall target or optimal BP & $54 \%$ & $31 \%$ & $23 \%$ \\
\hline Knowledge-seeking (internet search, books, magazines) & $23 \%$ & $8 \%$ & $15 \%$ \\
\hline \multicolumn{4}{|l|}{ Lifestyle } \\
\hline Diet-facilitators & $38 \%$ & $19 \%$ & $19 \%$ \\
\hline Diet-barriers & $58 \%$ & $27 \%$ & $31 \%$ \\
\hline Exercise-facilitators & $19 \%$ & $11 \%$ & $8 \%$ \\
\hline Exercise-barriers & $54 \%$ & $27 \%$ & $27 \%$ \\
\hline Salt and hypertension & $88 \%$ & $35 \%$ & $53 \%$ \\
\hline Weight & $50 \%$ & $15 \%$ & $35 \%$ \\
\hline Stress & $46 \%$ & $27 \%$ & $19 \%$ \\
\hline \multicolumn{4}{|l|}{ Feelings and beliefs of health and wellness } \\
\hline Physical manifestations & $57 \%$ & $15 \%$ & $42 \%$ \\
\hline \multicolumn{4}{|l|}{ Integration: routine } \\
\hline Routine to aid in medication adherence & $88 \%$ & $38 \%$ & $50 \%$ \\
\hline Coping with travel & $73 \%$ & $38 \%$ & $35 \%$ \\
\hline \multicolumn{4}{|l|}{ Healthcare providers } \\
\hline Facilitators & $69 \%$ & $31 \%$ & $38 \%$ \\
\hline Barriers & $54 \%$ & $23 \%$ & $31 \%$ \\
\hline
\end{tabular}

Patients indicated that healthcare providers did communicate information about hypertension; however, around half of patients had additional questions. Some patients perceived that their doctors were "too busy" to answer additional questions. Patients (69\%) mentioned that other healthcare providers, such as pharmacists and specialists, often provided more education than physicians.

3.4. Knowledge about Antihypertensive Medication. When asked about the function of medication, most patients did not know the exact mechanism of action of the pills. The consistent exception to this was diuretics, which patients referred to as a "water pill." Patients described the water pill as "flushing the system instead of building up," "makes you pee more," and "takes certain things out of your system like sodium and different things out of your blood stream." All patients viewed their BP medication as being all quite similar (i.e., did not believe that one was more "powerful" or "important" than another).

More than half of patients (69\%) attributed health issues to side effects from their antihypertensive medication.
Patients stated that they were comfortable and quick to discuss adverse effects with their doctor so that medication could be changed. The most commonly perceived side effects were edema (19\%), dizziness (19\%), increased urination $(15 \%)$, headaches $(12 \%)$, dry throat/cough $(8 \%)$, nausea and vomiting (8\%), loss of sexual desire (8\%), feeling lethargic (8\%), heartburn (4\%), hair loss (4\%), and constipation (4\%).

3.5. Knowledge Regarding Lifestyle. Patients understood that lifestyle modifications could decrease BP. The majority of patients (85\%) mentioned changes such as reducing salt intake and checking for sodium content (88\%), exercising (69\%), following a healthier diet (eating more fruits and vegetables) (69\%), losing weight (46\%), decreasing stress $(38 \%)$, quitting smoking (12\%), decreasing caffeine intake (8\%), and lowering alcohol intake (4\%). While quitting smoking does not decrease BP (CHEP 2011 guidelines), smokers did state that among ways to lower BP, quitting smoking would be relevant. Surprisingly, few patients (12\%) indicated that incomplete adherence to lifestyle modification advice was preventing them from decreasing medications. 


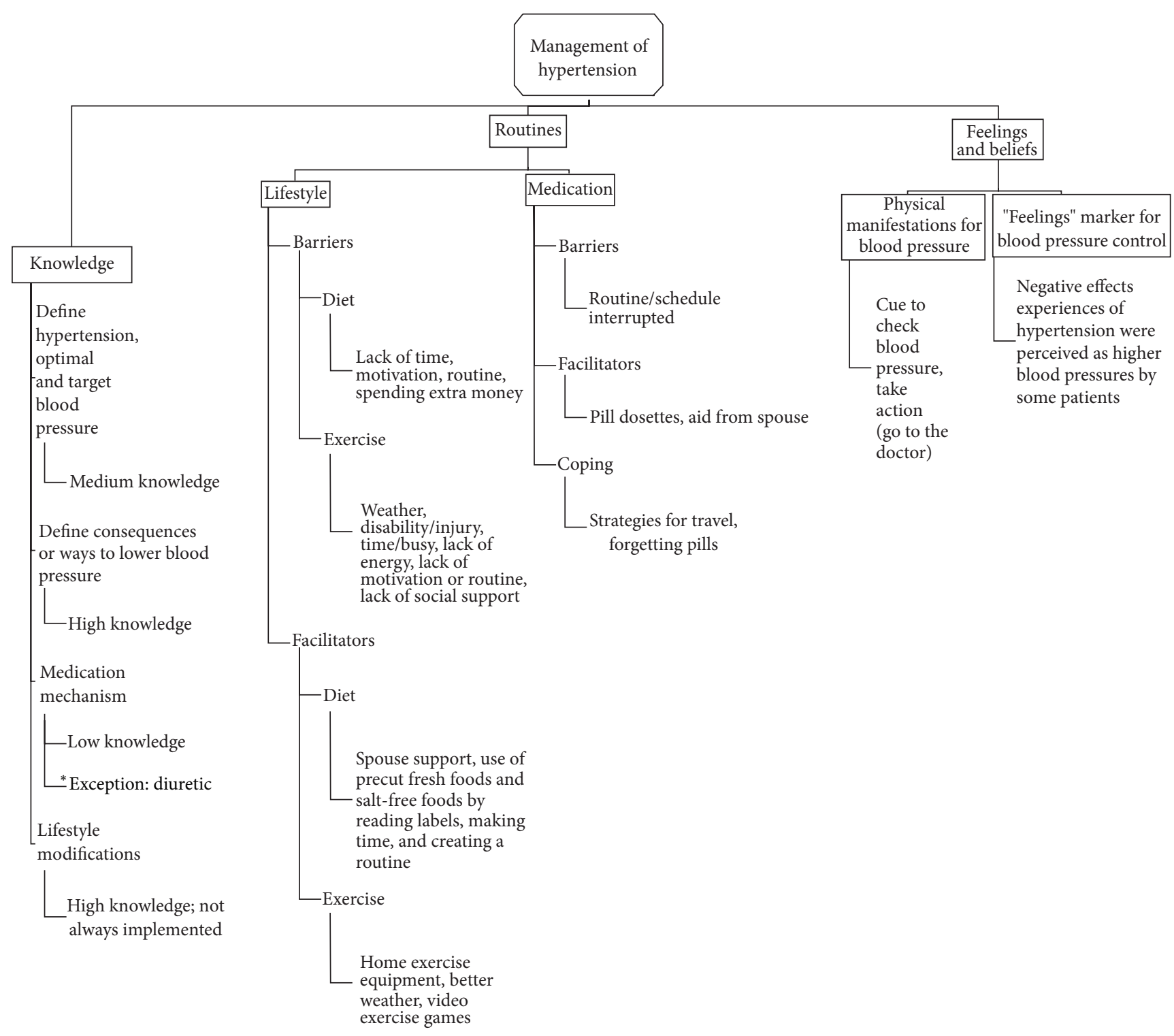

FIGURE 1: Diagram depicting key patient themes.

3.6. Pragmatism and Routines: Integration of Medication into Daily Life. The most frequently mentioned barrier to medication adherence was a lack of a structured routine or a change in the existing routine ( $88 \%$ mentioned routine) for self-administering BP medications (Table 4). Patients reported greatest success when they were able to seamlessly integrate their medication into their daily life. Patients had difficulty when schedules and routines were interrupted unless they had coping strategies to deal with these issues (e.g., carrying around extra pills and traveling with pill boxes). Of the $81 \%$ of respondents that commented on missed doses, $54 \%$ denied missing any dose and $27 \%$ reported that they "sometimes" missed a dose either due to forgetting or a change in routine. When asked what would happen if a dose was missed, respondents reported that they would take the next scheduled dose (and by doing so, they would miss a dose). Additionally, some stated that they may experience some side effects (headache, BP fluctuations, and feeling tired) from a missed dose. Monetary issues were only cited by $8 \%$ of patients.

Facilitators of adherence included having an established routine and using reminder tools to ensure medication is taken on a daily basis. Almost all patients (88\%) mentioned that using day-labeled pill boxes and making pills visible, along with establishing a routine that incorporates drug administration, ensured daily adherence. This could be summarized by one patient: “... Wash your face, brush your teeth, and take your pills" (male, on target). Patients described additional strategies to optimize adherence including pill counting prior to embarking on a trip and carrying special traveling boxes for extra pills in case that some were lost or misplaced. Lastly, $12 \%$ of patients mentioned that spouses and family members helped remind them to take their pills and refill their prescriptions. 
TABLE 3: Quotes of patients with respect to knowledge regarding blood pressure management.

\begin{tabular}{|c|c|}
\hline Theme & Quotes \\
\hline Knowledge & $\begin{array}{l}\text { Well it is definitely not a good thing for the body. I mean it can cause a lot of problems to kidneys and strokes } \\
\text { and you know make your heart work faster and therefore weaken it. You know, it is great when you exercise } \\
\text { and you get your heart going faster, but when your heart has to pump faster just to, kind of you know, deal } \\
\text { with your everyday life I mean it is not, it is not very clever at all. It is not very beneficial to you to have high } \\
\text { blood pressure. (female, on target) }\end{array}$ \\
\hline \multirow[t]{3}{*}{ Knowledge and HCP } & $\begin{array}{l}\text { P: Yeah I suppose I do not ask them because [-] I, I they will take the readings and they will vary. I assume } \\
\text { that if, if they had concerns they would ask me, and I do not want to be a hypochondriac or be a [chuckles] } \\
\text { asking rhetorical questions that do not really have an answer to them, so. And I sort of respect their time so } \\
\text { [-] and, and they might seem like silly questions so. }\end{array}$ \\
\hline & I: Do you get that feeling from something that they did or is that more? \\
\hline & $\begin{array}{l}\text { P: No, just respect their time and know that [-] I just maybe think they are [-] dumb questions perhaps or } \\
\text { taking up the doctor's time asking so. (male, on target) }\end{array}$ \\
\hline \multirow{5}{*}{ Knowledge and HCP } & $\begin{array}{l}\text { I: Do you have a good understanding about what high blood pressure is? So if your doctor was in the room } \\
\text { right now would you have questions for him that you still do not really understand? }\end{array}$ \\
\hline & P: What causes high blood pressure? Right. Why do they put you on medication, things like that. \\
\hline & I: Right. \\
\hline & P: They should answer that and talk about it. \\
\hline & $\begin{array}{l}\text { P: The only person who will do that [-] is a pharmacist. They will explain it more than the doctors. 'Cause } \\
\text { the doctors are in and out, they're so busy. (male, not on target) }\end{array}$ \\
\hline \multirow{2}{*}{ Knowledge: BP medication } & I: Do you have any idea of what it does for you? Or how it works or? \\
\hline & P: No. I do not. (male, not on target) \\
\hline Knowledge: BP medication & $\begin{array}{l}\text { I can't say as I do [know what each pill does], I know it's supposed to lower my blood pressure. So I know that } \\
\text { the water pill is very helpful. Um other than that, I do not know technically what mine does. (female, on } \\
\text { target) }\end{array}$ \\
\hline Side effects & $\begin{array}{l}\text { Um, no I mean [-] if the side effects, if the sexual thing was a proven side effect [-] I would have to make a } \\
\text { decision because [-] I might go off it just to see if it changed much. (male, on target) }\end{array}$ \\
\hline Side effects & $\begin{array}{l}\text { Yeah. No the other ones I was on were nasty. Like within, within four hours of taking it, I would be head over } \\
\text { the toilet bowl, sick, migraine [-] nasty. ․ but my hair was falling out and the pharmacist said, yeah the } \\
\text { diuretic can do that. So I asked my doctor, please change. And he went through this whole mess of all these } \\
\text { other ones that we were trying that just made me deathly ill. (female, not on target) }\end{array}$ \\
\hline Knowledge-lifestyle & $\begin{array}{l}\text { P: Yeah, well every time I go to the doctor [-] he always goes over it and you know tells me what I should be } \\
\text { doing. And I guess, if I did exactly what he said, more than likely I would not have high blood pressure. (male, } \\
\text { not on target) }\end{array}$ \\
\hline \multirow{8}{*}{ Knowledge-lifestyle } & $\begin{array}{l}\text { P: No I mean cognitively I know that stop smoking and lose weight and get active is the best thing you can do } \\
\text { for blood pressure. I am sure eating well and cutting out is probably another good thing too but I like salt so, I } \\
\text { mean I know what I should be doing it's just that I am not doing it. }\end{array}$ \\
\hline & I: Is that what it is or what is getting in the way? \\
\hline & P: Nothing, but sheer apathy. \\
\hline & P: Or [-] laziness. I sit at work all day. \\
\hline & $\begin{array}{l}\text { P: Maybe something happening? You'd think that two hundred over whatever it was blood pressure would } \\
\text { make me pick up and notice and start doing things but, I do not know, I really don't know. }\end{array}$ \\
\hline & $P:$ It is stupid, it is really stupid. \\
\hline & I: Not to do anything or? \\
\hline & $\begin{array}{l}\text { P: Yes! I am sixty for God's sake. I mean life is not getting any shorter or any longer. Do I need to be taking } \\
\text { care of this now. (female, on target) }\end{array}$ \\
\hline \multirow{5}{*}{ Knowledge-lifestyle } & $\begin{array}{l}\text { P: Yeah. I think, I do not know, maybe somebody would have to tell me, if you do not stop eating so much salt, } \\
\text { you're going to be dead in five years. }\end{array}$ \\
\hline & I: Okay. \\
\hline & $P:$ And then I'd be like oh crap, \\
\hline & I: So that would be your motivation? \\
\hline & P: Yeah. (female, not on target) \\
\hline
\end{tabular}


TABLE 4: Quotes of patients regarding routines in the management of their blood pressure.

\begin{tabular}{|c|c|}
\hline Theme & Quotes \\
\hline \multirow{3}{*}{ Routine } & $\begin{array}{l}\text { P: I've never missed it. I get right panicky if I have to miss it. And I know, you know the doctors have said, if } \\
\text { you miss one day it's not going to, you know, but I don't like to miss no. I don't miss. }\end{array}$ \\
\hline & I: What are you worried about if you miss? \\
\hline & P: Actually I can't tell you what I worry about, I just think it's not probably a good thing. (female, on target) \\
\hline Routine & $\begin{array}{l}\text { It really doesn't happen unless [-] um if schedules are all screwed up, if we're away somewhere or travelling } \\
\text { yeah. Which doesn't happen more than you know, a couple times a year. (female, not on target) }\end{array}$ \\
\hline Monetary issues & $\begin{array}{l}P: \text { Well it's not cheap. And then you know, it's like taking the medication right? I can't even afford it right now. } \\
\text { The healthier I stay, the better, cheaper it is for me. (male, not on target) }\end{array}$ \\
\hline Routine-support & $\begin{array}{l}\text { Yes sometimes wife tell me [-] [name] take all pills! Alright told [name] are you taking all together like this? } \\
\text { (male, not on target) }\end{array}$ \\
\hline Routine-coping & $\begin{array}{l}\text { I'm a frequent traveler so I carry my pills. Take them, take them and yeah I'm [-] very rarely might I miss a } \\
\text { day of taking them but most of the time I take them. (male, on target) }\end{array}$ \\
\hline Routine-coping & But it's quite easy when you have them in your little containers. (female, not on target) \\
\hline Routine-coping & $\begin{array}{l}\text { Oh I for years was really bad. I have a dosette now and I faithfully, got it all numbered the days of the month. } \\
\text { (male, not on target) }\end{array}$ \\
\hline Routine & $\begin{array}{l}\text { It's not going to be a problem. I've been doing it for years, So it's part of my ritual. It's just the way it is. You have } \\
\text { high blood pressure and you take it you don't forget. (male, on target) }\end{array}$ \\
\hline Lifestyle-barriers & $\begin{array}{l}\text { Um [-] but of course really the only setback is to that is because of my lifestyle I am very busy, and you don't } \\
\text { always have time to eat healthy. But that's, you know, you know I try and eat healthy and exercise as much as I } \\
\text { can. I think that's the part that stresses me out a little bit is that [-] um you know, I know I should be losing } \\
\text { weight and I know I should be doing it for my health, but I just have to get to I know it's important medically. } \\
\text { Um [-] you know but with lifestyle it is really hard to do that. (patient 13, female, on target) }\end{array}$ \\
\hline Routine-lifestyle & $\begin{array}{l}\text { Yeah sometimes weekends aren't the best for me [laughs] And I'm a bit worried about that if I retire 'cause I } \\
\text { think sometimes um [-] I eat a better diet on workdays because I have to make a lunch and take it. [-] I } \\
\text { think I'm just on more of a routine. (female, not on target) }\end{array}$ \\
\hline \multirow{3}{*}{$\begin{array}{l}\text { Dietary adherence-spousal } \\
\text { support }\end{array}$} & $P:$ And salt free diet, or salt reduced. \\
\hline & I: And how do you follow a salt free diet? \\
\hline & $P:$ My wife takes care of it. (male, on target) \\
\hline
\end{tabular}

3.7. Integration of Exercise and Diet Routine: Barriers and Facilitators. Barriers to maintain a healthy diet were mentioned by $58 \%$ of respondents (work schedule, too busy to cook, frequently eating out/prepared meals, lack of routine or motivation, and costs) and $38 \%$ mentioned facilitators (spouse support, use of precut fresh foods and salt-free foods, label reading, time management, and creating a routine) for healthy eating. Exercise barriers (weather, disability/injury, time/busy, lack of energy, lack of motivation or routine, and lack of social support) were mentioned by $54 \%$ of patients, while only $19 \%$ mentioned facilitators for increasing activity levels (exercise equipment or video games in home and better weather). Thoughts about being overweight were expressed by $50 \%$ of the patients ( $63 \%$ of females and $30 \%$ of males).

3.8. Feelings and Beliefs of Wellness. Despite hypertension often being described as being "silent" and asymptomatic, $69 \%$ of participants experienced symptoms that they attributed to elevated BP levels (Table 5) so that personal feelings and/or beliefs had an impact on hypertension management. Patients mentioned physical manifestations such as headaches (38\%), loss of energy, feelings of weakness/ tiredness (27\%), dizziness and light-headedness (19\%), water retention (19\%), and numbness (8\%). Thirty-one percent of the respondents felt that these symptoms were associated with fluctuations in their BP levels and appeared when their BP was not controlled. Participants used these symptoms as an indication of whether or not a BP measurement should be taken or a care provider seen. Others were motivated to improve their BP control because of fear of worsening symptoms or because of a positive family history. The majority of patients owned a BP machine (85\%) for home monitoring or would go to the drugstore for regular testing.

Over half of patients (62\%) mentioned that they wanted to reduce their antihypertensive pill burden or discontinue pills altogether. Twenty-three percent of the respondents reported trying nontraditional approaches and remedies before conventional drug therapy because they either did not want to take prescribed pills or felt there were "more natural ways" to lower BP.

\section{Discussion}

This study explored barriers to and facilitators of hypertension management from the patients' perspective by using semistructured interviews. Three recurrent themes were identified: knowledge, routines, and personal beliefs and feelings of wellness. Paradoxically, more knowledge about 
TABle 5: Patient quotes about feelings and beliefs of wellness.

\begin{tabular}{|c|c|}
\hline Theme & Quote \\
\hline \multirow{4}{*}{ Feelings and beliefs } & I: And how did you know it was going up and down? \\
\hline & $\begin{array}{l}\text { P: Well when I wasn't feeling well I [-] checked it.. And when I was feeling okay I just didn't check it. I just assumed } \\
\text { it's normal. [laughs] Not that much. But if I feel okay why would I worry about blood pressure? }\end{array}$ \\
\hline & I: Right. \\
\hline & $P:$ That's my feeling. (female, on target) \\
\hline \multirow{3}{*}{ Feelings and beliefs } & P: I find because my blood pressure I'm a bit tired. \\
\hline & I: Or how can you tell? \\
\hline & $P:$ I feel it. (female, not on target) \\
\hline \multirow{7}{*}{ Feelings and beliefs } & $\begin{array}{l}\text { I: Okay. So if you feel bad, do you assume it's your blood pressure or you know when, when it's high because you feel } \\
\text { a certain way? }\end{array}$ \\
\hline & P: Yeah. Yeah. \\
\hline & I: Okay. \\
\hline & P: You feel a certain way, you get flushed quite easily. \\
\hline & P: And uh [-] just don't, just don't feel like doing anything. \\
\hline & I: Okay. \\
\hline & P: Don't feel too energetic. (female, not on target) \\
\hline \multirow{5}{*}{ Feelings and beliefs } & $\begin{array}{l}\text { P: Like if I eat KFC or something like that I know my blood pressure is up the next day, you know by midnight she's } \\
\text { up there right? }\end{array}$ \\
\hline & I: Do you feel it or you just? \\
\hline & P: Oh yeah. \\
\hline & I: Oh, okay, what do you feel? \\
\hline & $\begin{array}{l}P:[-] \text { Sweaty. Like I can sleep [-] and I [-] like even with the window open tonight, I'll still be sweating. (male, } \\
\text { not on target) }\end{array}$ \\
\hline \multirow{7}{*}{ Feelings and beliefs } & P: I couldn't back then because it was high all the time. \\
\hline & I: You didn't really know. \\
\hline & $\begin{array}{l}P: \text { I didn't realize, but now I can tell the difference. I could tell when I retain water my hands swell [-] They get red, } \\
\text { if my blood pressure is really high. So, yeah it's really odd but yeah my hands get red, my feet swell, I can physically } \\
\text { feel it. }\end{array}$ \\
\hline & I: Going? \\
\hline & P: Yeah. \\
\hline & I: Okay. And do you feel any different if it's [-] low? Or lower? \\
\hline & $\begin{array}{l}\text { P: Yeah. Like I don't have any of those symptoms, I have no headaches, I don't have any [-] you know, swelling or } \\
\text { any of that kind of stuff. (female, not on target) }\end{array}$ \\
\hline \multirow{4}{*}{ Feelings and beliefs } & I: Can you feel a difference when it's low versus high? \\
\hline & P: Yes. \\
\hline & I: Can you tell me how? \\
\hline & P: Um I have more energy, definitely a lot more energy. That's probably the biggest. (female, on target) \\
\hline Natural remedies & $\begin{array}{l}\text { Well after um [-] probably a year and a half I realized that natural remedies don't work and um [-] I made an } \\
\text { appointment with my doctor. Well we went through a different process. (female, on target) }\end{array}$ \\
\hline
\end{tabular}

BP and its treatment was not associated with better control. Patients recognized the importance of routines for medication adherence; yet, they ascribed many symptoms to the side effects of drugs. Interestingly, physical and psychological factors were interpreted to be reflecting the prevailing BP level.

As mentioned, knowledge did not correlate with BP control in this study. This was remarkable, considering that the recruited patients were from specialist hypertension clinics, which distribute educational materials at the time of the appointment regarding optimal BP levels, home monitoring, lifestyle changes, and ways to lower BP. Other studies reported similar findings in regard to BP target knowledge and recall of information [14-16]. Knowledge regarding consequences of lifestyle changes and mechanisms of antihypertensive medication was not associated with control of hypertension. Similarly, an intensive nutritional intervention therapy (intense one-on-one educational sessions) for hypertensive patients increased knowledge but was not associated with improved dietary behaviour [17]. In summary, patient 
education can lead to increased knowledge about hypertension; however, this is not necessarily reflected in adaptations in behaviour [18] or, as this study shows, is not associated with better BP control.

Knowledge by itself may not impact adherence, but perhaps it is the way that knowledge is presented together with patient-related factors such as personal beliefs. For instance, patients mentioned that incomplete adherence to lifestyle modification was preventing them from reducing their pill burden. This indicates that patients are aware of the impact of lifestyle modifications, however, failed to translate this into implementation. Knowledge has been shown to enhance behaviour changes [19] in some studies but to a limited extent. Rigorous programs for behaviour change have shown improvements in patient BP. Self-management education interventions showed benefit for systolic BP [20], and intensive lifestyle medication in primary care showed a small reduction of BP [21]. Paradoxically, the absence of knowledge can potentially help adherence in that passive followers (those that do as the doctor tells them to do) may adhere better to medication. One study suggested that some patients adhere to medications simply because they generally follow rules (the study compared this to wearing a seat belt in the rear of the car [22]), or perhaps patients have trust in their doctor and medical plan [16]. On the contrary, patients without complete knowledge may have decreased adherence due to this lack of knowledge, along with personal beliefs that may conflict with management. In summary, it seems that individual patient factors and beliefs may act as barriers to applying knowledge, which underscores our limited insight in how to improve adherence to antihypertensive treatment.

A lack of a routine for medication use was the most frequently reported barrier to proper BP control. The presence of an established routine was identified as a key facilitator of achieving control. While not extensively described in the literature, habits and routine can impact management of hypertension [23]. The initiation of a routine to improve chronic disease management can be difficult for some because habits/routines that have been in place for years must be changed [24]. Complications arise further when multiple changes must occur. One study reported that patients were adherent to one piece of advice, however, had difficulties in simultaneously adhering to several medications and several lifestyle and monitoring changes [25]. Patients reported that disruption of routine, such as travel, in addition to interruptions of daily routines impaired adherence to medication and healthy lifestyle behaviours. When asked about daily medication adherence, the majority of patients denied missing a dose, and this finding that patients often overstate adherence in comparison to pharmacy refill data has been previously described in the literature [26]. In addition, adherence to lifestyle changes can be difficult for patients to integrate into daily life. Failure can be attributed to time constraints, lack of motivation, fatigue, cost, and a lack of motivation to make changes; prior data demonstrates that about $50 \%$ of patients have difficulties implementing diet and exercise $[27,28]$. While the majority of patients recognized that taking antihypertensive medicine was beneficial to their health, many were not at target BP levels, which suggest that patients' knowledge and disease awareness are not sufficient on their own to optimize BP control. Facilitators can significantly increase adherence, in addition to coping skills to assist with taking pills, reminders, and adhering to lifestyle changes. Ultimately, as seen from our study and current literature, routine is only one necessary part of medication adherence, however, a strong indicator of whether or not patients adhere to both medication and lifestyle changes for management of hypertension, over any other factors that were mentioned by patients. Patients with routine and the coping skills to adapt to changes in routine may fare best with medication adherence and maintaining lifestyle changes. One limitation to the current study is that we are unaware of how many patients actively used "routine" for their HTN management, or if routine was already a part of everyday life.

Our study reveals that patients' feelings and beliefs of wellness can impact adherence to physician recommendations of daily medication and lifestyle changes. Despite clinical literature that describes hypertension as asymptomatic, our findings are consistent with other qualitative studies where patients describe physical symptoms of hypertension [29]. It should be remarked that this observation does not provide evidence to state that hypertensive patients have specific complaints that differ from a group of healthy agematched subjects. Yet, it has relevance. As indicated by our data, we found that those patients who experienced negative effects associated with hypertension also believed that their BPs were higher. Patients used the way they feel and their perceptions of their health to self-monitor their BP and to determine BP actions (take a BP measurement, consume medication, or go to the hospital). Obviously, this is not desirable, although for some this may support adherence and serve as motivation to adhere to medication. However, for others who believe that hypertension is symptomatic and who do not experience physical symptoms, such beliefs may interfere with adherence to medical advice and with home assessment of BP [30]. This observation has obvious consequences for patient education.

Perception of disease is important as well. In a study of hypertensive patients, those that rated their overall health as good/excellent were less likely to have controlled hypertension, along with those younger ( $<45$ years) and those unaware of family history [31]. About $75 \%$ of patients in our study mentioned benefits to taking the medications; however, this was not related to BP control. One study suggests that patients may attribute the effectiveness of their medications to their overall sense of well-being and/or the presence or absence of physical symptoms [30]. Beliefs can depend on patient characteristics, psychological factors [32], sociocultural context [33], and values [34]. Altogether the role of patient feelings and beliefs of wellness may have a very substantial impact on adherence and could be a strong indicator regarding the intention to change behaviour.

\section{Conclusion}

Summarizing, we identified several individual patient issues relevant to the treatment of hypertension. Patient knowledge, routines, and beliefs about their health could interfere with 
hypertension management. This suggests combining educational materials with more intense behavioural modifications, including coping and changes in routine, and incorporating principles of health literacy and cultural competence could bring benefit to hypertension management. Lastly, the role of the provider is "the most important interaction in ensuring adequate medication adherence" [35], which could play a role in the patients' belief system. Building upon the existing research to develop an instrument to assess patients' personal barriers could have widespread relevance for better control of BP.

\section{Acknowledgments}

The authors would like to thank the patients who participated in this study and Ms. Melisa Spaling for her input and suggestions for the paper. The Department of Medicine and Alberta Health Services supported this study (Emerging Team Grant). Dr. Braam is a Heart and Stroke Foundation of Canada New Investigator.

\section{References}

[1] F. A. McAlister, K. Wilkins, M. Joffres et al., "Changes in the rates of awareness, treatment and control of hypertension in Canada over the past two decades," CMAJ, vol. 183, no. 9, pp. 1007-1013, 2011.

[2] M. N. Hill, N. H. Miller, and S. Degeest, "Adherence and persistence with taking medication to control high blood pressure," Journal of the American Society of Hypertension, vol. 5, no. 1, pp. 56-63, 2011.

[3] A. Dragomir, R. Côté, L. Roy et al., "Impact of adherence to antihypertensive agents on clinical outcomes and hospitalization costs," Medical Care, vol. 48, no. 5, pp. 418-425, 2010.

[4] R. B. Haynes, E. Ackloo, N. Sahota, H. P. McDonald, and X. Yao, "Interventions for enhancing medication adherence," Cochrane Database of Systematic Reviews, no. 2, Article ID CD000011, 2008.

[5] E. P. Jolles, A. M. Clark, and B. Braam, "Getting the message across: opportunities and obstacles in effective communication in hypertension care," Journal of Hypertension, vol. 30, no. 8, pp. 1500-1510, 2012.

[6] L. Osterberg and T. Blaschke, "Adherence to medication," The New England Journal of Medicine, vol. 353, no. 5, pp. 487-497, 2005.

[7] K. S. Ingersoll and J. Cohen, "The impact of medication regimen factors on adherence to chronic treatment: a review of literature," Journal of Behavioral Medicine, vol. 31, no. 3, pp. 213-224, 2008.

[8] J. Y. Lam and L. M. Guirguis, "Patients' blood pressure knowledge, perceptions and monitoring practices in community pharmacies," Pharmacy Practice, vol. 8, no. 3, pp. 187-192, 2010.

[9] U. Subramanian, T. P. Hofer, M. L. Klamerus, B. J. ZikmundFisher, M. Heisler, and E. A. Kerr, "Knowledge of blood pressure targets among patients with diabetes," Primary Care Diabetes, vol. 1, no. 4, pp. 195-198, 2007.

[10] S. Ross, A. Walker, and M. J. MacLeod, "Patient compliance in hypertension: role of illness perceptions and treatment beliefs," Journal of Human Hypertension, vol. 18, no. 9, pp. 607-613, 2004.

[11] R. Wexler, T. Elton, A. Pleister, and D. Feldman, "Barriers to blood pressure control as reported by African American patients," Journal of the National Medical Association, vol. 101, no. 6, pp. 597-603, 2009.

[12] M. A. Krousel-Wood, P. Muntner, T. Islam, D. E. Morisky, and L. S. Webber, "Barriers to and determinants of medication adherence in hypertension management: perspective of the cohort study of medication adherence among older adults," Medical Clinics of North America, vol. 93, no. 3, pp. 753-769, 2009.

[13] E. H. Bradley, L. A. Curry, and K. J. Devers, "Qualitative data analysis for health services research: developing taxonomy, themes, and theory," Health Services Research, vol. 42, no. 4, pp. 1758-1772, 2007.

[14] S. Cheng, J. H. Lichtman, J. M. Amatruda et al., "Knowledge of blood pressure levels and targets in patients with coronary artery disease in the USA," Journal of Human Hypertension, vol. 19, no. 10, pp. 769-774, 2005.

[15] D. Samal, S. Greisenegger, E. Auff, W. Lang, and W. Lalouschek, "The relation between knowledge about hypertension and education in hospitalized patients with stroke in Vienna," Stroke, vol. 38, no. 4, pp. 1304-1308, 2007.

[16] C. Taylor and A. Ward, "Patients' views of high blood pressure, its treatment and risks," Australian Family Physician, vol. 32, no. 4, pp. 278-282, 2003.

[17] E. Racine, J. L. Troyer, J. Warren-Findlow, and W. J. McAuley, "The effect of medical nutrition therapy on changes in dietary knowledge and dash diet adherence in older adults with cardiovascular disease," Journal of Nutrition, Health and Aging, pp. 1-9, 2011.

[18] C. Magadza, S. E. Radloff, and S. C. Srinivas, "The effect of an educational intervention on patients' knowledge about hypertension, beliefs about medicines, and adherence," Research in Social and Administrative Pharmacy, vol. 5, no. 4, pp. 363-375, 2009.

[19] L. A. Mooney and A. M. Franks, "Impact of health screening and education on knowledge of coronary heart disease risk factors," Journal of the American Pharmacists Association, vol. 51, no. 6, pp. 713-718, 2003.

[20] A. Warsi, P. S. Wang, M. P. LaValley, J. Avorn, and D. H. Solomon, "Self-management education programs in chronic disease: a systematic review and methodological critique of the literature," Archives of Internal Medicine, vol. 164, no. 15, pp. 1641-1649, 2004.

[21] M. K. Eriksson, P. W. Franks, and M. Eliasson, "A 3-year randomized trial of lifestyle intervention for cardiovascular risk reduction in the primary care setting: the Swedish Björknäs study," PLoS ONE, vol. 4, no. 4, Article ID e5195, 2009.

[22] G. Reach, "Obedience and motivation as mechanisms for adherence to medication: a study in obese type 2 diabetic patients," Patient Preference and Adherence, vol. 5, pp. 523-531, 2011.

[23] E. S. Cohn, D. E. Cortés, G. Fix, N. Mueller, J. L. Solomon, and B. G. Bokhour, "Habits and routines in the daily management of hypertension," Journal of Health Psychology, vol. 17, no. 6, pp. 845-855, 2012.

[24] K. Charmaz, "The self as habit: the reconstruction of self in chronic illness," Occupational Therapy Journal of Research, vol. 22, no. 1, 2002.

[25] S. Uzun, B. Kara, M. Yokuşoǧlu, F. Arslan, M. Birhan Yilmaz, and H. Karaeren, "The assessment of adherence of hypertensive individuals to treatment and lifestyle change recommendations," Anadolu Kardiyoloji Dergisi, vol. 9, no. 2, pp. 102-109, 2009. 
[26] P. S. Wang, J. S. Benner, R. J. Glynn, W. C. Winkelmayer, H. Mogun, and J. Avorn, "How well do patients report noncompliance with antihypertensive medications?: a comparison of selfreport versus filled prescriptions," Pharmacoepidemiology and Drug Safety, vol. 13, no. 1, pp. 11-19, 2004.

[27] M. E. Gee, A. Bienek, N. R. Campbell et al., "Prevalence of, and barriers to, preventive lifestyle behaviors in hypertension (from a national survey of Canadians with hypertension)," The American Journal of Cardiology, vol. 109, no. 4, pp. 570-575, 2012.

[28] M. R. Weir, E. W. Maibach, G. L. Bakris et al., "Implications of a health lifestyle and medication analysis for improving hypertension control," Archives of Internal Medicine, vol. 160, no. 4, pp. 481-490, 2000.

[29] P. Schlomann and J. Schmitke, "Lay beliefs about hypertension: an interpretive synthesis of the qualitative research," Journal of the American Academy of Nurse Practitioners, vol. 19, no. 7, pp. 358-367, 2007.

[30] E. Brondolo, R. C. Rosen, J. B. Kostis, and J. E. Schwartz, "Relationship of physical symptoms and mood to perceived and actual blood pressure in hypertensive men: a repeated-measures design," Psychosomatic Medicine, vol. 61, no. 3, pp. 311-318, 1999.

[31] R. G. Victor, D. Leonard, P. Hess et al., "Factors associated with hypertension awareness, treatment, and control in Dallas County, Texas," Archives of Internal Medicine, vol. 168, no. 12, pp. 1285-1293, 2008.

[32] V. S. Okken, M. G. Niemeijer, A. Dijkstra et al., "The effect of physical, social and psychological factors on drug compliance in patients with mild hypertension," Netherlands Heart Journal, vol. 16, no. 6, pp. 197-200, 2008.

[33] I. M. Kronish, H. Leventhal, and C. R. Horowitz, "Understanding minority patients' beliefs about hypertension to reduce gaps in communication between patients and clinicians," The Journal of Clinical Hypertension, vol. 14, no. 1, pp. 38-44, 2012.

[34] C. Michaels, M. M. McEwen, and D. B. McArthur, "Saying "no" to professional recommendations: client values, beliefs, and evidence-based practice," Journal of the American Academy of Nurse Practitioners, vol. 20, no. 12, pp. 585-589, 2008.

[35] G. Harmon, J. Lefante, and M. Krousel-Wood, "Overcoming barriers: the role of providers in improving patient adherence to antihypertensive medications," Current Opinion in Cardiology, vol. 21, no. 4, pp. 310-315, 2006. 


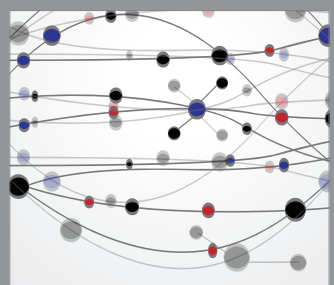

The Scientific World Journal
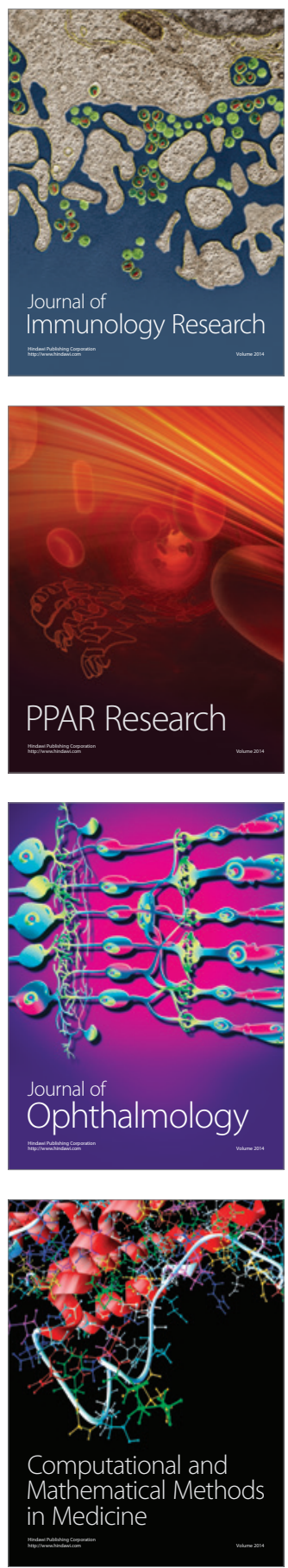

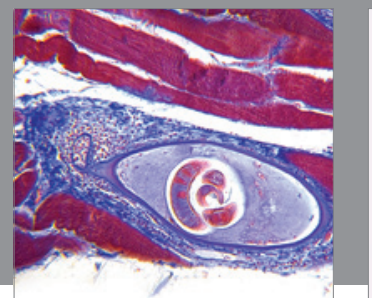

Gastroenterology

Research and Practice
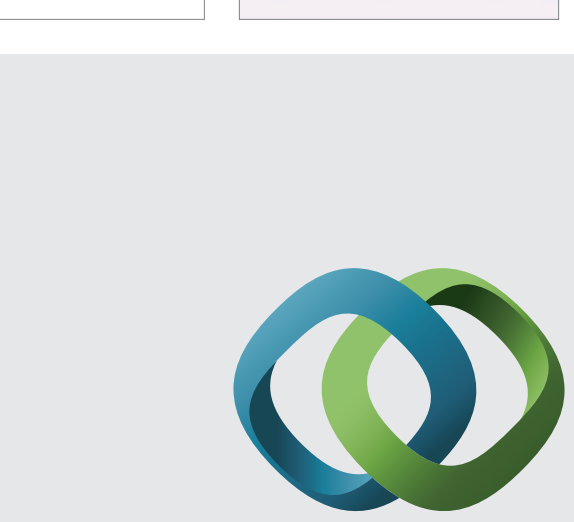

\section{Hindawi}

Submit your manuscripts at

http://www.hindawi.com
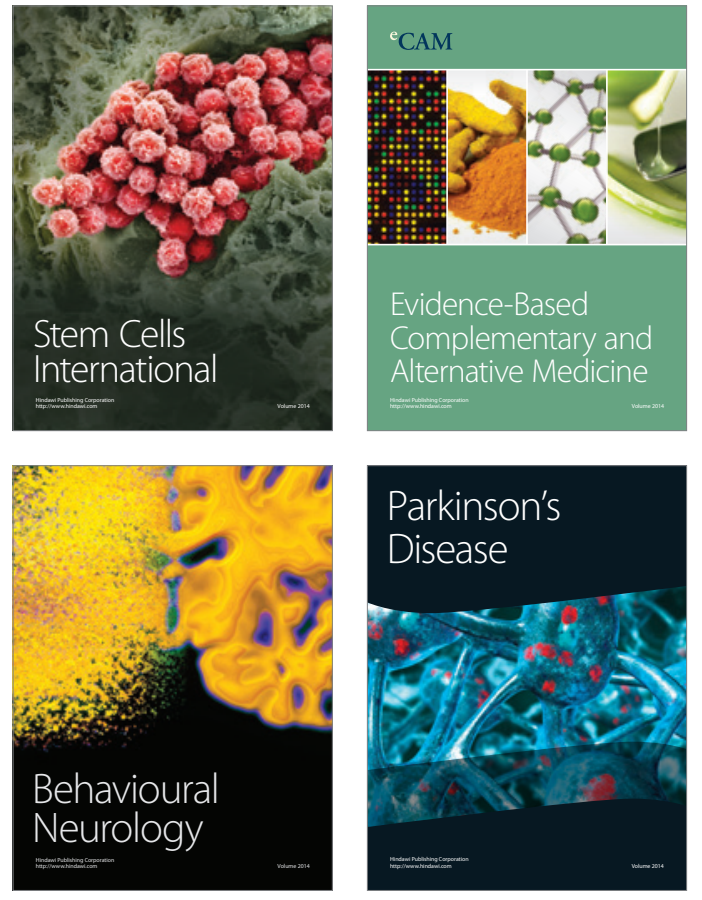
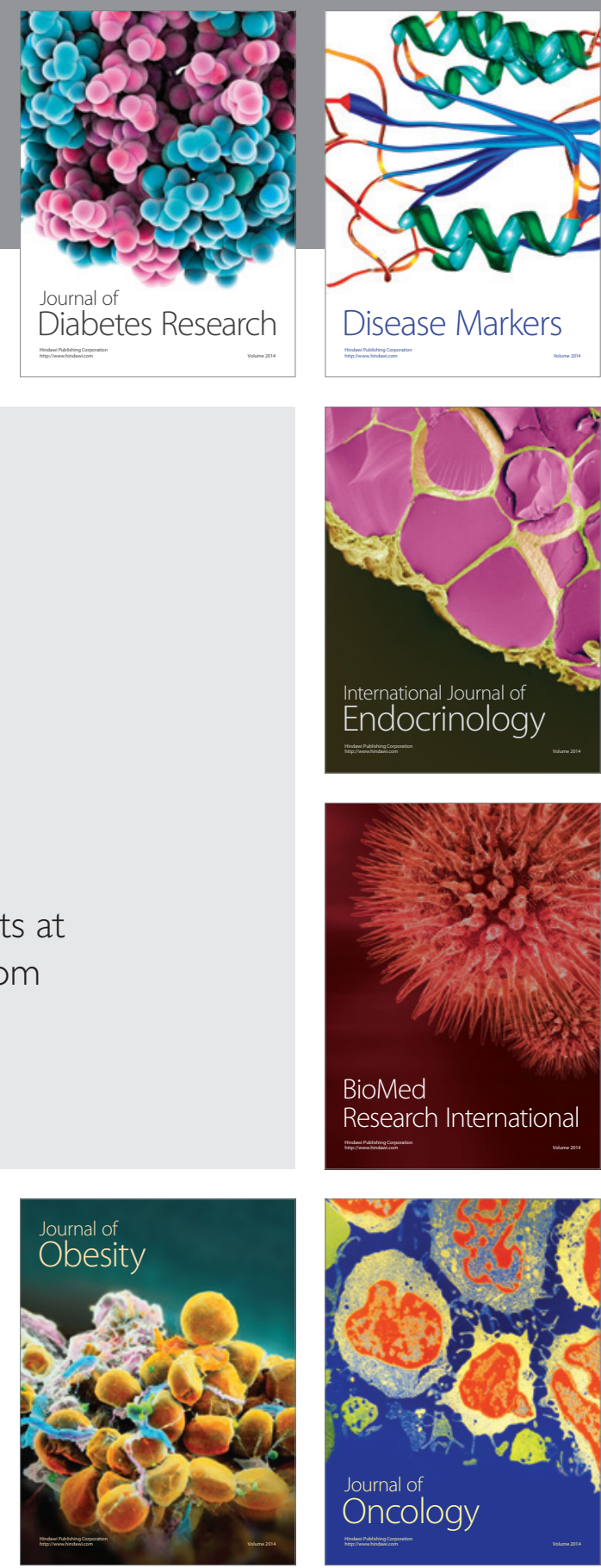

Disease Markers
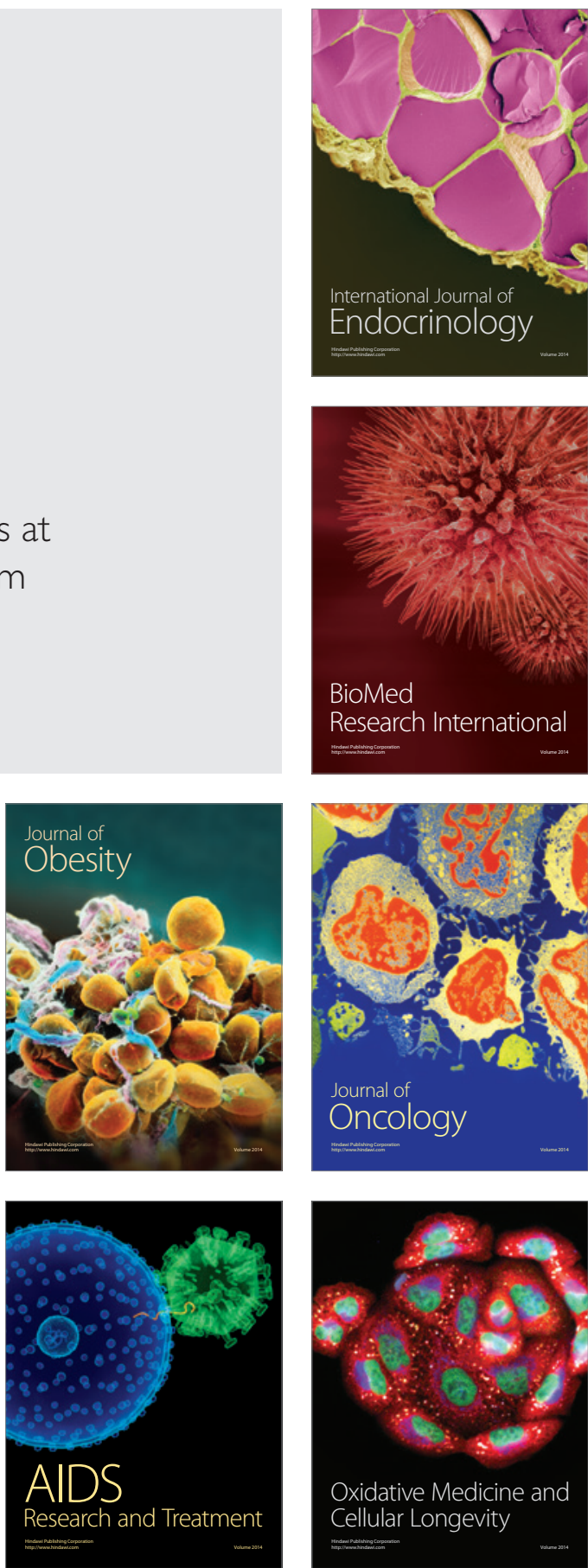